\title{
Barriers and bridges between mother tongue and English as a second language in young children
}

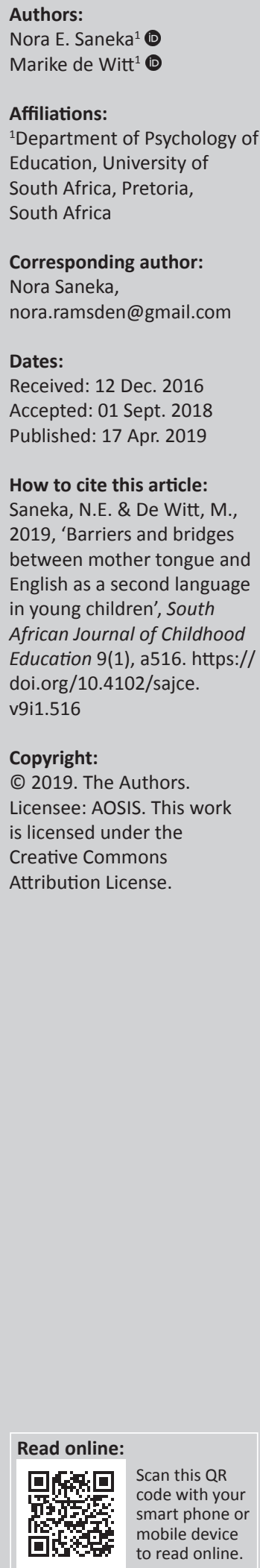

Background: Social and economic aspirations held by parents can reflect a desire for their children to learn English as a second language. Bilingual education has the potential for empowering traditionally disadvantaged groups, particularly through competence in English, a language that positions identity with power, privilege and status, thus being a political and an economic issue.

Aim: The aim was to look critically at the language development of young second-language learners within their social context.

Setting: An early childhood centre in Durban, South Africa.

Methods: Methodologically, a qualitative praxeological framework was used. Parent partnership in sustaining the mother tongue was sought and explored in focus group interviews, using an action-reflection cycle to understand the dilemma of young second-language learners in South Africa. Ways of overcoming language barriers using the strengths of the child were explored using persona dolls. These methods helped to develop sustained, shared thinking between children, their parents and the researcher.

Results: Young children found their own means of engaging in meaning-making processes both at home and at school. The issue of linguicism was tackled by encouraging parental participation in sustaining the mother tongue while children learned English as a second language.

Conclusion: As long as English means access to improved economic opportunities, there will be a bias against those whose home language is not English. The dilemma of the young English language learner remains an issue of equity, access and redress for past injustices.

Keywords: parent participation; the young second-language learner; the right to participation; socio-constructivism; critical constructivism; praxeological research.

\section{Introduction}

The purpose of this research was to look critically at the language development of young second-language learners within their social context, in relation to theory and practice (praxis). Language and communication are seen as fundamental to the child's right to participation, according to the United Nations Convention on the Rights of the Child (1989). Young children, seen as agents of their own life, find their own means to engage in meaning-making processes both at home and at school. In this research, different ways were explored to overcome language barriers using this strength of the child, in the process documenting the child's capabilities to share with the parents and in discussion with them, to build up an image of identity of each child. The research became a means of encouraging parent participation in sustaining the mother tongue while the child learned English as a second language, that is, additive bilingualism.

Social and economic aspirations held by parents for their children can reflect a desire for their children to learn English as a second or additional language. Robb (1995:19) argues that bilingual education has the potential for empowering traditionally disadvantaged groups, particularly through competence in English, a language that positions identity in relation to power, privilege and status. Therefore, it is not just a political issue but also an economic issue.

The dilemma of the young English language learner from a lower socio-economic environment is that additive bilingualism means more; however, the mother tongue tends to be subtracted in favour of English. This results in what is known as subtractive bilingualism - to the detriment of the young child. Additive bilingualism can add complexity of thought; the young child can think conceptually beyond the restrictions of the one right word to multiple perspectives. 
Added vocabulary can also add a richness and complexity to thought. However, this type of intellectual development, mediated through more than one language and culture, is seen in elite bilingualism as additive bilingualism. Elite bilingualism develops within higher socio-economic classes where families provide books in both languages and have the leisure time to support the mother tongue as well as the additional language(s). In such families, high levels of conceptual skills are encouraged in both English and the mother tongue. However, children from lower socio-economic communities tend to have parents who are faced with many challenges including a lack of formal education, the low social status of their mother tongue and a lack of time if they work long hours away from their children. Their mother tongue may also not have a value within the formal education system or the economy. Common bilingualism as subtractive bilingualism or semilingualism tends to develop (Toukomaa 2000:215). The child may have acquired basic interpersonal communication skills in the second or additional language of English, but finds difficulty with cognitive academic language proficiency (Cummins 1979). This is the dilemma of the young second or additional language learner.

Children can also develop an arrogance when they use English because language use reveals social positioning. This can manifest in what has been termed 'linguicism' (Phillipson 2007). When children become more schooled than their parents or grandparents (in South Africa this schooling would be in English), this can lead to an intergenerational breakdown in communication. Wong Fillmore (1991:323-346) describes the resulting lack of respect of children for their older family members and loss of traditional family values or the wisdom of the elders.

Therefore, linguicism refers to the hegemony of language, the language spoken by the dominant social class. In South Africa, this tends to be English, possibly left over from the colonial era, where English has become a language seen as holding status and power. A family's mother tongue does not have this advantage. In spite of the Constitution, not much happens at grassroots level to enforce indigenous language use in South Africa. Children become aware of subtle social cues and see the power in language from their parents and are aware of non-dominant languages. Language ties in with race, ethnicity and social class which in turn reflect unequal access to resources in terms of job opportunities, social status and political power. English has its power in being the language of global communication.

Active collaboration between school and home becomes important, especially when the teachers do not speak the home language(s) or mother tongue. The early years are a vital period of time, but in this research the English language learner was already showing a choice to speak English in preference to the home language(s) or mother tongue. It was also seen that some parents encouraged their children to speak English as a home language even when their own spoken English was very limited (Saneka 2014:128).
Similar results have been found from research in other countries: '... they may refuse to use their home language anymore as it is difficult to use both, and English may have greater status in the children's eyes' (Gordon \& Browne 2008:490). Wong Fillmore (1991) went so far as to suggest that learning a second language means losing the first.

The Republic of South Africa's (1997) language-in-education policy is that of additive bilingualism. The particular preprimary school used in this research has been registered under the South African Department of Basic Education. It follows the curriculum and has both Zulu- and Xhosaspeaking teachers as well as English-, French- and Afrikaansspeaking teachers. However, as there is a need for children to be prepared for English-medium primary school education, English is the language of learning and teaching. Therefore, English is spoken by the teachers and English is the language the children are encouraged to use in response. The children are also free to converse with each other during free play in whichever language they prefer.

Issues arise for the mother tongue, particularly for children who come from disadvantaged backgrounds. This is especially the case when, according to Heugh (1995:179), the young English language learner receives such a strong, positive message about English in contrast to that of his or her mother tongue. Therefore, this research sought ways of encouraging the parents of young children to sustain mother tongue practice in the home while their child learned English as a second language in an early childhood centre situated in a lower socio-economic area.

\section{Research methods and design}

The setting for this study was an early childhood centre in a lower socio-economic area in Durban, South Africa. At the time of this research, 90 children within the age range 2-6 years old attended this centre and were educated at Grade 000, 00 and 0 (or $R$, the reception year) levels in preparation for entering school at the Grade 1 level. In terms of the nature of the research approach used, these children together with their parents and five teachers formed an inclusive purposive sample.

The researcher as a practitioner in the early childhood centre used a participatory action research methodology within a praxeological conceptual framework, using a socio-cultural and critical theoretical framework to examine practice (praxis). She used this methodology to explore the interface between the role players, the socio-cultural language context and interventions which could affirm the importance of sustaining the mother tongue of the young child while he or she was learning English as a second language. Parent partnership in sustaining the mother tongue was sought and explored in focus group interviews, with an action-reflection cycle used to understand the dilemma of the young secondlanguage learner in South Africa. While participation was open to all parents, there were 16 who participated in the 
first round of focus group interviews and 8 in the second round 5 months later.

The inclusion of children as participants was motivated by the right to participate (United Nations General Assembly 1989), where participation was seen as a lens through which to critically examine values and beliefs. As Carla Rinaldi (2006:101) says: 'It is the value of research, but also the search for values'. Aims (reflecting our values) and methods (pedagogical practice) can be conceived of as closely interlinked. These aims and methods are socio-cultural in nature and therefore reflect how the norms and values of language practice are shaped and developed within a social and historical context.

In working with the children and their teachers, different methods were used in the research process to explore ways of overcoming language barriers using the strengths of the child. These methods, as '100 ways of listening to children' (Clark 2007:77) ultimately helped to develop 'sustained, shared thinking' between the children, their parents and the researcher and co-construction of knowledge around language practices (Siraj-Blatchford et al. 2002:10). Specifically, for this research, persona dolls were used (Saneka 2014):

Persona dolls are used as a 'tool' for the implementation of antibias education and are a means to 'narrate and create' the persona doll's life-story, in dialogue with the children. Each doll has its own 'persona', family history and individual identity. This is seen as a non-threatening way to include issues of language, identity, culture, race, class, and other anti-bias issues. The story of each doll is recorded in their 'I.D. Book' which can also be a type of 'journal' of the events in that doll's life as it is a record of the dialogue between the doll and the insights of the children. Children's participation (the dialogue between the 'persona doll' and the children) enables the story of the doll's life-situation to unfold in terms of how she/he (the persona doll) reacts and responds to the events in his/her life, with questions, suggestions and advice from the children. Each time he or she visits the children and 'chats' to them, the persona doll gives the children a 'voice' to express their thoughts and fears, hopes and struggles, leading the children from interpersonal awareness to intrapersonal awareness. The doll can become a 'mirror' to reflect the children's life-situation back to them, in order for them to reach a deeper understanding of their own thoughts and feelings and learn to empathize with the feelings of others, including the persona doll. (pp. 110-111)

Data were obtained from observing the behaviour of the children when interacting with the persona dolls. A picture of the persona dolls may be seen in Figure 1.

The research followed a praxeological methodology to discern the principle of the best interests of the child in relation to the right to participation and language practice at home and school (United Nations General Assembly 1989). Praxeology can lead to critical reflection on practice, particularly when using dialogue with others on subjective perceptions and values in relation to knowledge and experience (Pascal \& Bertram 2012:480-486). According to Saugstad (2002:380-381), the Aristotelian description of

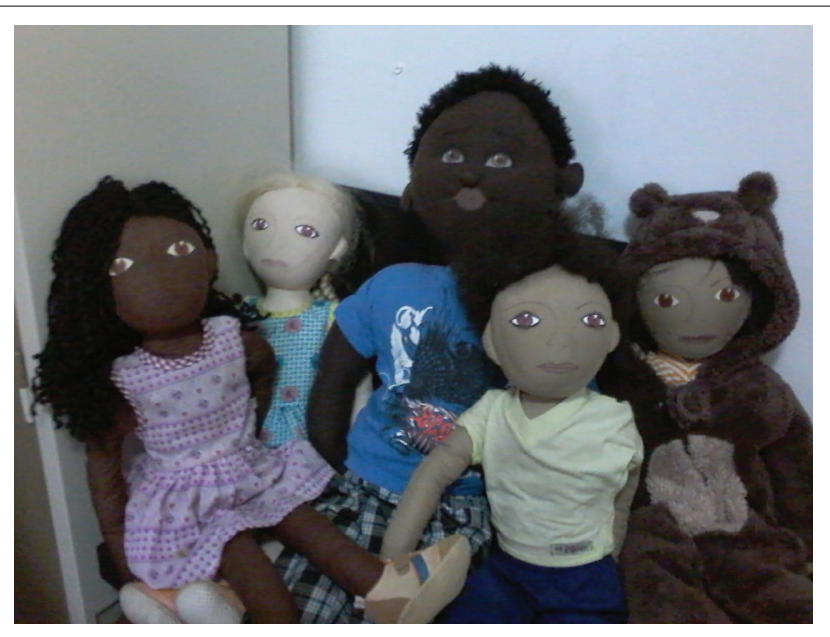

Source: Photo courtesy of Nora Elizabeth Saneka.

FIGURE 1: Persona dolls.

knowledge is not just episteme ('factual knowledge' or 'universal, certain, eternal, general, non-contextual and abstract knowledge') but knowledge developed through praxis, incorporating values and ethics. Phronesis, through 'knowledge of political, social and ethical practice' becomes 'an ability to act morally correctly on the basis of the correct deliberations' (Saugstad 2002:380-381). Similarly, Pascal and Bertram (2012:486) outlined six principles for praxeological research, namely that it is ethical, democratic, critical, subjective, systematic and action based. These can all be seen as relevant to research on language practice, as the research could then explain the social and cultural context within which meaning-making develops, as well as provide the means of enquiring into the dilemma of the young secondlanguage learner, with a view to transformative action to motivate and support parents.

\section{Ethical considerations}

This research received ethical clearance from the University of South Africa College of Education Research Ethics Committee (Reference Number 2013 MAY 4056485/CSLR).

\section{Results}

There were four broad sets of results, namely observations from interaction with the teachers, the first focus group interview, the second focus group interview and observations from the use of the persona doll. These findings are presented briefly here and explored in more depth in the discussion.

The interaction with the teachers is provided as anecdotal and used for background purposes as the teachers did not sign consent for participation in this research at this stage. There were weekly review meetings to discuss concerns and plan interventions. Concerns raised included observations that languages have different dialects, with Zulu being no exception. With its different dialects, the question of what pure Zulu is was raised. Some dialects can sound like slang. Thus, the purity of the mother tongue was challenged. Further challenges were noted where parents 
chose not to speak their mother tongue to their children, as well as children opting to speak English in preference to their mother tongue.

The first focus group interview with 16 parents was able to identify the advantages of English easily. It was argued that English is a universal language and makes it easy to communicate throughout the world. They also felt that English was necessary in education, particularly at tertiary level, as concepts are not easily translatable. Furthermore, they noted that there are not enough books available in the mother tongue. Additionally, the mother tongue became problematic when trying to communicate with their children on a number of levels - it was useful for discussing problems when children were younger than 4 years old, but older children would respond in English. The breakdown of communication also became intergenerational - when children went back home to the rural areas, they could not communicate with their grandparents who now saw their grandchildren as having a 'white' education and the grandparents doubted the value of this. Children would be labelled terms like 'coconut' (black on the outside and white on the inside). The parents noted that their children understood their mother tongue but refused to speak it to parents because of the school environment with much exposure to English. Finally, the parents were concerned about their children being isolated and bullied if they spoke only one language against a majority who spoke another language. They felt one language alone was incomplete and another was needed for better understanding.

There was a conceptual shift in the second focus group interview with 8 parents which took place 5 months later. It was noted that children isolated themselves from other Zulu-speaking children in the townships and would not play with them. English became the language of choice even if they were spoken to in an indigenous language such as Zulu. As the children were attending the centre in a lower socio-economic area, there was also the issue of exposure to 'street English' where the language usage would come across as rudeness and was seen as a culturally unacceptable way of speaking, for example, swearing. Thus, English was seen as not all good, especially when sounding disrespectful. It was necessary to promote the mother tongue home language, such as in having more story books available in other languages. It was difficult to reprimand in the second language as children could ignore their own language or block it out. Therefore, it was important to hold on to identity and family values, and language was tied to identity and power.

The use of the persona dolls with the children was a useful way to dialogue with them where they could identify on common ground, develop empathy and develop friendship, thus being able to discuss problems and situations. Thus, the dolls gave the children a chance to be heard, thereby also helping parents to communicate with their children, and the children would not be excluded by language. Specific instances of persona doll interactions are explored in depth in the next section.

\section{Discussion}

Children reached out intentionally to others seeking information and through gesture and language, used different modes and means of expression. They showed their curiosity: they investigated, expressed their ideas and feelings and wanted to be taken seriously (United Nations General Assembly 1989, Article 12). Some of the modes and means of expression in the research included painting and drawing, wooden block construction and outdoor play with water and sand. They also took their own photographs to show what their likes and dislikes were in their school environment. The research broadened the idea of participation from mere consultation to ways of listening to children for adults to understand their point of view. As Lansdown (2005) points out, a culture of listening to children is not generally the norm for adults (cited in Morrow \& Richards 1996:97).

A central concern in the research was that children who are learning in a second or additional language can be silenced in many ways. This is why using the right to participation and children's rights as a lens for critical reflection on the research process emphasised the right to seek, receive and impart information, share experiences and ideas (United Nations General Assembly 1989, Article 13) and hold one's own opinion on matters (United Nations General Assembly 1989, Article 14). Of course, these rights are dependent on respectful and inclusive adult support and guidance (Lansdown 2004:5), as well as taking into account the evolving capacities of the child, as discerned by the adults (United Nations Committee on the Rights of the Child 2005:42). The challenge for adults was to take account of the abilities, strengths and ways children expressed their own ideas, including the culture of childhood. In actualising these rights, we are informed that we have a duty to consider 'the best interests of the child as a primary concern' (Organization of African Unity (OAU) 1990, Article 3, (1) and Article 4; United Nations General Assembly 1989). However, there may be differing cultural and social perspectives on the value of the mother tongue or home language(s) in relation to English - a language of power. Therefore, the 'best interests' principle can become a matter of interpretation, contestation and debate between parents, children and teachers. In the postapartheid situation, additive bilingualism is also a political question of equity and access.

Language as co-construction of meaning, but also of selfexpression or identity, is shaped by the socio-cultural context. Affirming the child's emotions in the mother tongue as well, English becomes an important way for the child to develop empathy with others (Saneka 2014:131): 'Through others, we become ourselves' (Vygotsky 1931). This resonates with the deep African philosophical value of $u B u n t u$, showing humanity, expressed as 'umuntu, ngumuntu, ngabantu'. This is translated as 'a person is a person because of other people'. 
In Africa this can be seen as expressing both humaneness as care or empathy for the other, and social solidarity. This can challenge us to ask the question about what kind of society we want and how our actions realise the values of that society. Many of the children in this research were enrolled in the early childhood centre to learn English because of the perceived social and economic advantage, but could become 'an English-speaking someone' which would cause a barrier between themselves and their friends at home (Saneka 2014:283).

The results of the research in the second focus group discussion revealed a perceived powerlessness experienced by the parents in the face of what seemed to be this choice or option for English made by their children, even when they spoke the mother tongue to them (Saneka 2014:159), and, in the case of one child, when he had had a Zulu-speaking teacher for the past 2 years (Saneka 2014:162). However, by the end of the research both the parents and the teachers were more aware of the issues in relation to language, power and identity. At the second focus group discussion, which concluded the research, a parent stated emphatically: 'The children must not lose their identity, but cling onto it and carry on with everything else. They must plant that one tree, then grab whatever they can, from everything else!' (Saneka 2014:294). Article 29 (c) of the United Nations Convention on the Rights of the Child (AOU 1989) stipulates the critical importance of:

... the development of respect for the child's parents, his or her own cultural identity, language and values, for the national values of the country in which the child is living, the country from which he or she may originate, and for civilizations different from his or her own. (p. 9)

The sense of belonging, which can come through interactions with peers, family or their teachers, is said to be a way to create 'a caring community of learners' (NAEYC 2009:16). A sense of belonging is essential for an infant to thrive and later for the well-being of the young child, as seen in attachment theory (Richter 2004:15). However, those who are perceived as not belonging may experience discrimination, bullying or teasing and the child may feel forced to conform to peer pressure, including in language practices.

\section{The problem of linguicism}

A crucial factor in the child's language development is the child's attitude towards the second or additional language(s), the value given to these languages by the parents and motivation to use the mother tongue. As an illustration, in the research process a newly enrolled Zulu-speaking child was observed by teachers in the fantasy play area, which they said was like a 'mother tongue nest', playing silently on the old computer while the other children were chatting to each other in their mother tongue, Zulu. In going through what has been termed the initial silent period while learning English, she was silent even in the midst of this busy hive of activity, surrounded by children speaking her mother tongue. Over the next couple of months at her school, single words in
English and Zulu slowly started emerging and she proved to be highly verbal.

Some of the parents from the Congo were also choosing to speak English to their children at home, rather than their own mother tongue or French, another international language, even though their own proficiency in English was limited. Their children were identified as 'inventing imaginary words' or 'using formulaic speech to fill the gap' (Saneka 2014:128, 238).

Children were also seen to get the message that a way of speaking, an accent or certain language including English but not limited to English, is of higher prestige than others. However, this can create a barrier. For example, some of the teachers who spoke the mother tongue or home language(s) tended to use it for the discipline or correction of the child (Saneka 2014:129) and not for 'sustained shared thinking' (Siraj-Blatchford et al. 2002:10). Interactive conversation, playful exchanges of ideas, storytelling and other teaching situations were all in English, which seemed to reinforce the authority of English with the authority of the teacher (Saneka 2014:285). A parent also reported reprimanding his son in the mother tongue, before switching to English (Saneka 2014:279). Therefore, this encouraged a negative association with the mother tongue or home language(s). However, a parent also reported that her son only listened to her if she reprimanded him in English, instead of the mother tongue (Saneka 2014:286), '[b]ecause it's about power, and children love power' as the parent explained.

In one example, which was discussed by a parent at the first focus group discussion, his child had started testing adult attitudes to social norms of communication, in order to see how his parent would respond. The parent experienced difficulties with the child's lack of cooperation, especially when his child showed defiance. He was upset when his child shouted at him: 'No, no!', as that was interpreted as showing disrespect as it went against his social norms and values (Saneka 2014:268). Some of the other children also tested the limits by deliberately blocking out words in the home language with white noise, and one parent reported her child as saying 'Blah, blah, blah' while she attempted to talk to her (Saneka 2014:282) and showed selective hearing to avoid responding to her parent. Language use also revealed insiders and outsiders and a type of power play between the children as a form of linguicism (Saneka 2014:261).

The following two examples from the research are illustrative of this linguicism (Saneka 2014:151-154):

In the first example, 'Lunga' had to come to terms with a newly enrolled boy who started in August who had been brought up by his Zulu-speaking grandmother on the farm and could not speak any English. 'Lunga' started teasing him because he could not speak English. This happened although he himself could not speak any English at the beginning of the year and was also brought up by his 
grandmother, who only spoke Zulu and who travelled with him each day from an informal township area outside of the city and dropped him off on her way to work. When told of her grandson's prejudice against the new boy, she was horrified and said she would beat him up, saying this in Zulu! The teacher, together with her translator - one of the general assistants - persuaded her that this would not be the answer to the problem. The conflict between the two boys continued the next day when 'Lunga' thought it would be fun to smash a ball, a sphere constructed out of hexagonal shapes, that the new boy had not been able to construct for himself and which another friend had constructed for him. He had been cherishing it, because he found it too difficult to make himself. After being spoken to in their mother tongue by a Zulu-speaking teacher's assistant, they resolved the conflict and seemed to come to an understanding. They found a private space in a car constructed from a cardboard box in which they could pull down the visor and chat privately to one another.

The yellow hexagonal shapes had been shared by them and they were relaxing, as can be seen in Figure 2.

In the second example, one day, one of the boys started 'slaughtering' a cow at the dough table, using a plastic knife and shouting out the traditional terminology for the parts of the cow he was cutting off - the hooves, the head, and so on. This caused a lot of excitement and four other boys came to join him, including 'Luyanda', whose family background was Xhosa, and whose mother, in the course of a parent interview and in the first focus group discussion, had said that he was now choosing to speak English over Xhosa. She expressed some concern about it, particularly with regard to family functions in the township and her child's participation in these. 'Luyanda' came up with Xhosa terminology for slaughtering his cow, which was laughed at by the other boys who were using Zulu terminology. He then retreated into his shell, switching off from the celebratory mood of the other boys who were slaughtering their cows for the feast.

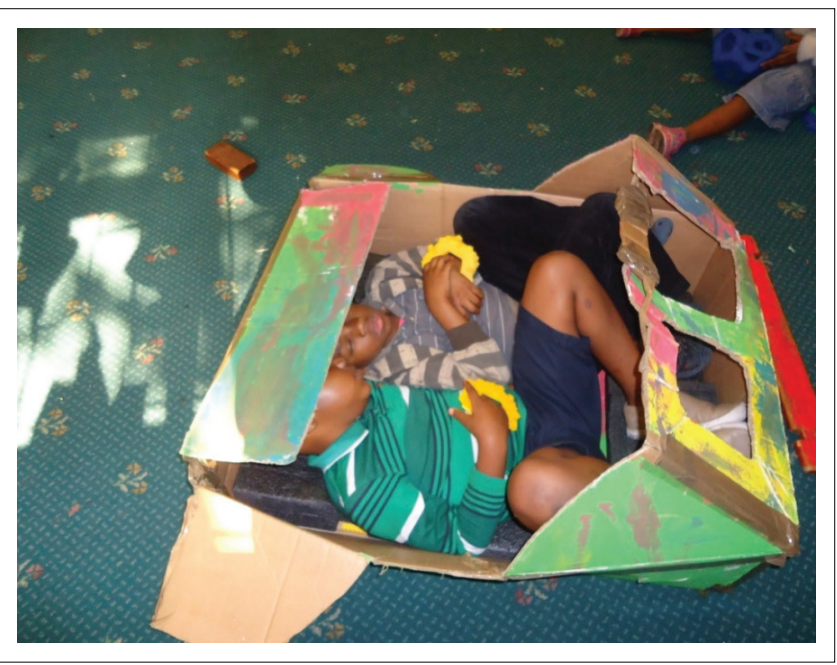

Source: Photo courtesy of Nora Elizabeth Saneka.

FIGURE 2: The understanding after the conflict had been resolved.
The concern is that frustration in communication and a sense of lack of respect towards others can lead to the use of force or violence. In our early childhood settings, children, in their interactions with each other, can also seem to reflect the needs and problems of the society around them. Various other problems with regard to observed prejudice against languages other than English were discussed by the teachers in the review meeting in a process of reflection-on-action, leading to reflection-to-action. For example, at the beginning of the year the Zulu-speaking teachers had reported that some of the children used to laugh when a Zulu-speaking teacher used Zulu in conversation, which also happened when Afrikaans words were used, such as teaching the children to greet in Afrikaans in the morning. Some of the Zulu-speaking staff members had also criticised the type of Zulu spoken by another staff member.

During a class where persona dolls were used, certain children also showed disrespect in the way they initially treated a Zulu-speaking persona doll called 'Sipho' (second from the right in the front row in Figure 1), pulling down his pants 'accidently' to see if he was a boy and acting roughly towards him. The purpose of the persona doll approach is to address issues of bias, prejudice, discrimination, bullying and to embrace diversity (Smith 2009:4). Therefore, this persona doll Sipho came to visit the children and chatted about his family, his likes and dislikes including the sleeping arrangements in his home, a small two-roomed house in a low-income semiurban informal settlement. The persona doll Sipho visited the children regularly after this initial negative experience, and Sipho became their friend. He chatted about his grandmother who only spoke Zulu and his own preschool. Sipho had his own difficulties including bullying and teasing because the children with whom he played only wanted to talk to him in English. The aim of the persona doll approach was to develop an empathy for Sipho and for his struggles to be understood. His own language and culture were appreciated when he came to visit the children and chat about exciting events, such as a traditional family wedding he attended, a shopping trip, a visit to the farm and other positive events in which his ability to speak Zulu was an asset, together with the teacher's ability to speak Zulu and interpret what he was saying. The negative perception of Sipho in relation to his poverty and lack of English was alleviated. It was only when the children had connected with him in a positive way through the wedding that Sipho could speak through the teacher about his own problems at school and seek the advice and support of the children so that they accepted him as a friend (Saneka 2014:154).

It seems an anti-bias curriculum using the persona doll approach can become a vitally important means for children to express their thoughts and feelings and develop empathy for others. It can construct a positive self-identity as well as group identity. This is particularly important when children move between languages and between diverse ways of thinking (Gordon \& Browne 2008:151) as they transition between home and school. Derman-Sparks and the ABC Task 
Force (1989) indicated that an anti-bias curriculum aims to develop in children a knowledgeable, confident self-identity and group identity, empathic interaction with people from diverse backgrounds, critical thinking and problem-posing about issues of bias, and an ability in the child to stand up for fairness and justice. This seems of critical importance in our post-apartheid society which is still marked by inequality, bias, prejudice and stigma. Anti-discrimination and respect for human dignity is integral to the South African Constitution and the Bill of Rights (Republic of South Africa 1996, Chapter 2).

The anti-bias curriculum can use the persona doll method effectively to support children's rights. The persona doll also has rights, for example, it has a name (the 'right to a name', United Nations General Assembly 1989, Article 7) and a personal identity, a life situation and a particular social context and need to belong. These all help the children to relate to real-life issues and problems which the persona doll mirrors to the children. The method of dialogue with the children helps them to empathise with the persona doll as it chats to them (Smith 2009:4). The persona doll confides in the children and receives their advice, becoming a means to empower children to change situations for the better. In this way, the persona doll in this research created a safe space for children to talk about their own situations and problems and share their feelings, opinions and ideas with each other. This finding supports Derman-Sparks and the ABC Task Force (1989), as cited by Smith (2009:114), in the third goal of the anti-bias curriculum: 'Each child will increasingly recognize unfairness, have language to describe unfairness, and understand that unfairness hurts', and in the fourth goal: 'Each child will demonstrate empowerment and the skills to act, with others or alone, against prejudice and/or discriminatory actions'.

\section{Conclusion}

The relevance of this research was that it examined the relationship between the educational environment of the school, the teaching commitment of the practitioner researcher and the social and political context of South African language-in-education policy (Pascal \& Bertram 2012:484). This particular process was chosen as a conscious way of developing attentiveness and awareness (reflection-in-action and reflection-on-action) (Schön 1987:26) as well as acceptance of responsibility (reflection-to-action) in order to work towards transformation in language practices (Formosinho \& Oliveira Formosinho 2012:600). In using this methodology, the researcher as practitioner aimed at phronesis or wise practice, using the child's right to participation as a lens for critical reflection (United Nations Committee on the Rights of the Child 2009).

The post-Vygotskian socio-cultural theory that was used in conjunction with critical theory created the possibility for an interpretation of the social and cultural interactions of the children. Lev Vygotsky believed 'thinking depends on speech, on the means of thinking, and on the child's socio- cultural experience' (Vygotsky 1987:120, as quoted in Woolfolk 2007:42). This research looked specifically at language practices, in which the researcher used a praxeological methodology starting with a focus group discussion with the parents to engage their participation and ending the research process with a second focus group discussion. Language practices were seen as arising from the needs and aspirations of the society in which the child lives. The social and cultural interactions arising from these interactions are responsible for how the child chooses to use language, which can also create barriers in communication. One of the areas which was identified as an opportunity, but also a danger, was the verbalisation of the parent or teacher for the child. The choice of language by parent or child in different situations presented different kinds of challenges. In this research, identity ('who am I?') as subjectivity ('I am because you are') can be revealed through language choice, by teachers, parents and children. Critical theory was used to examine the nature of the child's language development and the perceived choice of the child to opt for English and powerlessness of the parents. This research attempted to affirm the important role of the parents if they continued to use the mother tongue and home language(s) at home. However, some parents placed the responsibility firmly back on the teacher - 'the children so much respect the teacher's authority' (Saneka 2014:285).

The research revealed that it is important to explore ways of affirming the role of the young child as an agent of his or her own life, while looking at the culture of childhood, power and subjectivity (identity) in relation to English as a second or additional language and the role of the mother tongue. In particular, the relationships children, parents and teachers form with each other are of vital importance (Malaguzzi 1993). In this research, the young learner revealed a sensitivity to cultural and linguistic cues resulting in a bias as to the relative value of languages in relation their home languages, even between the Southern African Nguni languages (Saneka 2014:152).

In the culture of childhood (Saneka 2014:143), there are many different modes and means of expression besides verbal language that need to be affirmed. There are also many ways of listening and responding to children in their search for meaning. In this regard, praxeology is an important methodology for developing critical, reflective practice and involving the parents in becoming more aware of the dilemma of the young English language learner and also being supported by teachers. Parents and teachers can both become conscientised (Freire 1972) as to their vital role in supporting the home language(s) and mother tongue while the child learns English.

The lens of the right to participate (United Nations General Assembly 1989) highlighted issues such as the perceived choice of language by children and who they choose to play with, bias and discrimination against those who speak a different language or are from different social and economic circumstances, and prejudice against those who are seen as 
black, poor and uneducated in comparison to those who speak English. It seems that as long as English is the means of access to improved economic opportunities, there will be a bias against those whose home language is not English. In South Africa, the dilemma of the young English language learner remains an issue of equity, access and redress for past injustices.

\section{Acknowledgements Competing interests}

The authors declare that they have no financial or personal relationships that may have inappropriately influenced them in writing this article.

\section{Authors' contributions}

N.E.S. wrote the article. Material was taken from an unpublished Master's dissertation in educational psychology, University of South Africa. M.D.W. was the Master's supervisor for N.E.S.

\section{References}

Clark, A., 2007, 'A hundred ways of listening: Gathering children's perspectives of thei early childhood environment', Young Children 62, 3-76.

Cummins, J., 1979, 'Linguistic interdependence and the educational development of bilingual children', Review of Educational Research 49(2), 222-251. https://doi. org/10.3102/00346543049002222

Derman-Sparks, L. \& The Anti-Bias Curriculum (ABC) Task Force, 1989, Anti-bias curriculum: Tools for empowering young children, National Association for the Education of Young Children (NAEYC), Washington, DC

Formosinho, J. \& Oliveira Formosinho, J., 2012, 'Towards a social science of the social: The contribution of praxeological research', European Early Childhood Education Research Journal 20(4), 591-606. https://doi.org/10.1080/135029 3X.2012.737237

Freire, P., 1972, Cultural action for freedom, Penguin Books Ltd., Harmondsworth.

Gordon, A.M. \& Browne, K.W., 2008, Beginnings and beyond, 7th edn., Delmar Learning, Albany, NY.

Heugh, K., 1995, 'From unequal education to the real thing', in K. Heugh, A. Siegruhn \& P. Pluddemann (eds.), Multilingual education for South Africa, pp. 37-41, Heinemann, Johannesburg.

Lansdown, G., 2004, Young children's participation: Rhetoric or growing reality? Early Childhood Matters 103, Bernard van Leer Foundation, viewed 20 July 2012, from www.bernardvanleer.org

Lansdown, G., 2005, Can you hear me? The right of young children to participate in decisions affecting them, Working paper 36, Bernard van Leer Foundation, viewed 20 July 2011, from www.bernardvanleer.org

Malaguzzi, L., 1993, transl. L. Gandini, 'For an education based on relationships', Young Children 49(1), 9-13.

Morrow, V. \& Richards, M., 1996, 'The ethics of social research with children: An overview', Children and Society 10, 90-105. https://doi.org/10.1111/j.1099-0860.1996. tb00461.x
NAEYC, 2009, 'National association for the education of young children', in Position statement: Developmentally appropriate practice in early childhood programmes statement: Developmentally appropriate practice in early child hood programmes
serving children from birth through to age 8 , viewed 14 August 2012, from www. naeyc.org/files/naeyc/file/positions/PSDIV98

Organization of African Unity (OAU), African Charter on the Rights and Welfare of the Child, 1999, viewed 23 August 2018, from http://www.achpr.org/files/ instruments/child/achpr_instr_charterchild_eng.pdf

Pascal, C. \& Bertram, T., 2012, 'Praxis, ethics and power: Developing praxeology as a participatory paradigm for early childhood research', European Early Childhood Education Research Journal 20(4), 477-492. https://doi.org/10.1080/135029 3X.2012.737236

Phillipson, R., 2007, 'Realities and myths of linguistic imperialism', Journal of Multilingual and Multicultural Development 18(3), 238-248. https://doi.org/ 10.1080/01434639708666317

Republic of South Africa, 1996, Constitution of the Republic of South Africa, Bill of Rights, Chapter 2, viewed 27 January 2019, from www.justice.gov.za/legislation/ constitution/SAConstitution-web-eng.pdf

Republic of South Africa, 1997, Language in education policy 14 July 1997, Department of Education, Pretoria. https://www.education.gov.za/Portals/O/Documents/ Policies/GET/LanguageEducationPolicy1997.pdf?ver=2007-08-22-083918-000

Richter, L., 2004, The importance of care-giver child interactions for the survival and healthy development of young children: A review, Department of Child and Adolescent Health, World Health Organization, Geneva.

Rinaldi, C., 2006, In dialogue with Reggio Emilia: Listening, researching and learning, Routledge, London.

Robb, H., 1995, 'Multilingual preschooling', in K. Heugh, A. Siegruhn \& P. Pluddemann (eds.), Multilingual education for South Africa, pp. 15-22, Heinemann, Johannesburg.

Saneka, N., 2014, 'Barriers and bridges: Child participation, second-language learning and the cognitive development of the young child', Unpublished Masters Dissertation, Department of Education, UNISA.

Saugstad, T., 2002, 'Educational theory and practice in an Aristotelian perspective', Scandinavian Journal of Educational Research 46(4), 373-390. https://doi. Scandinavian Journal of Education
org/10.1080/0031383022000024561

Schön, D.A., 1987, Educating the reflective practitioner: Toward a new design for teaching and learning in the professions, Jossey-Bass Inc., San Francisco, CA.

Siraj-Blatchford, I., Sylva, K., Muttock, S., Gilden, R. \& Bell, D., 2002, Researching effective pedagogy in the early years, Research Report No 356, Institute of Education, University of London, Department of Educational Studies, University of Oxford, Queen's Printer, Norwich.

Smith, C., 2009, 'Persona dolls and anti-bias curriculum practice with young children: A case study of early childhood development teachers', Unpublished Masters Dissertation, Department of Education, University of Cape Town.

Toukomaa, P., 2000, 'The linguistic problem child has many names', in R. Phillipson (ed.), Rights to language, equity, power and education, pp. 214-218, Lawrence Erlbaum Associates, Mahwah, NJ.

United Nations General Assembly, 1989, Convention on the Rights of the Child, viewed 23 August 2018, from https://downloads.unicef.org.uk/wp-content/uploads/2010/05/ August 2018, from https://downloads.unicef.org.uk/wp-content/uploads/2010/05/
UNCRC PRESS200910web.pdf? ga $=2.262342796 .1609654975 .1535033831-$ UNCRC PRESS200910

United Nations Committee on the Rights of the Child, 2006, General comment No. 7: Implementing Child Rights in Early Childhood, (CRC/C/GC/7/Rev.1,) viewed 27 January 2019, from https://www.refworld.org/docid/460bc5a62.html

United Nations Committee on the Rights of the Child, 2009, General Comment No. 12: The right of the child to be heard (CRC/C/GC/12), viewed 27 January 2019, from www.refworld.org/docid/4ae562c52.html

Vygotsky, L.S., 1931, Genesis of higher mental functions, paragraph 55, viewed 24 August 2018, from https://www.marxists.org/archive/vygotsky/works/1931/ higher-mental-functions.htm

Vygotsky, L.S., 1987, 'Thinking and speech', in R.W. Reiber \& A.S. Carton (eds.), The collected works of L.S. Vygotsky, vol. 1: Problems of general psychology, pp. 39-285, N. Minick, translator, Plenum, New York.

Wong Fillmore, L., 1991, 'When learning a second language means losing the first', Early Childhood Research Quarterly 6, 323-346. https://doi.org/10.1016/S08852006(05)80059-6

Woolfolk, A., 2007, Educational psychology, 10th edn., Pearson Education, Boston, MA. 